\title{
ORIGINAL ARTICLE \\ Spinal Cord Injury: Scenario in an Indian State
}

\author{
N Mathur, S Jain, N Kumar, A Srivastava, N Purohit and A Patni
}

Study design: Prospective observational study.

Objectives: To find out the epidemiology and demographic factors associated with patients of traumatic spinal cord injury (SCl). Setting: Sawai Man Singh Medical College and Hospital, Jaipur, India.

Methods: Consecutive SCl cases admitted from January 2000 to December 2008 were evaluated on a preformed proforma for demographic factors, epidemiological data and neurological status.

Results: In 2716 cases of SCI, 1400 were cervical and 1316 thoracolumbar, with male to female ratio of $4.2: 1$ and $71 \%$ in the age group of 20-49 years. Around $79 \%$ patients were from rural background. About $23.3 \%$ were farmers while $22.9 \%$ were laborers. Among the causes of injury, $53 \%$ patients had a fall from height and $28 \%$ suffered from road traffic accidents. Fall of heavy object over head and back (10.7\%), fall with heavy object over head (3.0\%) and fall following electric shock (4.0\%) were uncommon causes. Complete paralysis was found in $20.5 \%$ cervical and $23.3 \%$ in thoracic injuries. Extremity and rib fractures (10.6\%) and head injuries (7.2\%) were common associated injuries. About $55 \%$ cases were initially attended at non-specialized centers. Proper bladder and bowel management in early phase was lacking.

Conclusion: Epidemiological factors of $\mathrm{SCl}$ in Indian scenario are different from western countries with major cause being fall. The low socio-economic status and younger age group had a major financial, social and psychological impact as majority of the patients were the primary earning members of the family. Therefore, measures should be taken to reduce the incidence of SCl.

Spinal Cord (2015) 53, 349-352; doi:10.1038/sc.2014.153; published online 16 September 2014

\section{INTRODUCTION}

Spinal cord injury (SCI) is a life threatening condition that carries a high risk of morbidity and mortality. Various epidemiological studies have been carried out in different parts of the world. The incidence of SCI varies from 9.2 to 56.1 per million, ${ }^{1-13}$ which is influenced not only by research methodology but also by social, economic, geographical, demographic and political characteristics of the region. ${ }^{4,9,10,14}$ Although India is the second most populous country in the world, to date no demographic data are available for SCI. Therefore, a study was conducted to determine the demographic and epidemiological data and neurological status of patients with SCI in India.

\section{MATERIALS AND METHODS}

This prospective observational study was conducted from January 2000 to December 2008 in the Spinal Unit of the Department of Physical Medicine and Rehabilitation, in our tertiary care hospital. All consecutive cases of SCI admitted in the department were evaluated for neurological status according to the International Standards for Neurological Classification of Spinal Cord Injury, including the American Spinal Injury Association Impairment Scale (AIS). ${ }^{15}$ A prestructured proforma was used for evaluation which included demographic parameters such as age, gender, marital status, locality, educational status, income, type of family, profession and the number of family members dependent on patient. In the epidemiological variables, mechanism of injury, time of arrival in our unit after injury, mode of transport used during transfer of patient, position of patient during transfer, any previous hospitalization, the type of care provided during initial admission at other health-care facility and associated injuries were noted. Some useful terminologies used in the article are appended (Appendix).

The patients admitted in other departments or institutions or those who expired before reaching the department were excluded from this study. Data are presented as number (\%) or ratio.

\section{RESULTS}

Out of 8178 cases admitted in the department during the study period, 2716 cases $(23.2 \%)$ were of SCI. Complete paralysis (AIS type A) below the injury level was found in 557 and 633 cases in cervical and thoracolumbar injuries, respectively. Those patients who did not allow neurological evaluation were grouped as 'not tested' patients (Table 1). In all, 1400 cases of cervical SCI and 1316 cases of thoracolumbar SCI, involving 2194 males (80.8\%) and 522 females (19.2\%) were admitted and managed during this period. About $79 \%$ patients were from rural and $21 \%$ from urban area in the ratio of $3.7: 1$. Seventy-one percent cases were in the age range of 20-49 years (Table 2). One thousand twenty-eight patients (37.8\%) were uneducated (without formal education in any institute). In all, $1389(51.1 \%)$ of these patients were living in a nuclear family while 832 cases $(30.6 \%)$ resided in joint family. The average monthly earning of their family was Rs 3000 only (US\$ 60, UKE 37.5).

In total, 632 farmers (23.3\%) and 622 laborers (22.9\%) sustained spinal injury resulting from different mechanisms (Table 3 ). Three hundred forty-seven females (12.8\%) sustained spinal injuries while working in the field. In all, 1449 patients (53.4\%) sustained injuries 
following fall from height followed by 762 cases (28\%) of road traffic accident (RTA). In rural population, out of 1145 patients (42.2\%) who sustained injury following fall, 577 patients $(21.2 \%)$ had fall from roof top. Ninety-nine patients (3.6\%) sustained spinal injuries following fall in a dry well while digging or accidentally. Eighty-four patients (3\%) sustained trauma following fall of heavy object over head, which is a common mode of transportation of goods in rural areas. Two hundred ninety-one patients (10.7\%) sustained injury following fall of heavy object over back while removing mud from dry well for increasing its depth or placing or removing grain bags in storage area. One hundred ten patients (4\%) sustained trauma following fall from electric pole or height following electric shock. Besides SCI they sustained electric burns also (Table 4). This was an unusual mode of trauma noticed in our patient population.

In all, $699(25.7 \%)$ patients sustained different types of associated injuries out of which 588 patients $(84.1 \%)$ sustained major injuries, with or without abrasion, lacerated wound or electric burn. In all, 293 patients $(41.1 \%)$ had single or multiple fractures or dislocation at different sites, 195 patients $(27.8 \%)$ sustained simple head injury which resolved in few days and 51 patients $(7.3 \%)$ sustained multiple rib fractures. The major injuries were more common in patients sustaining SCI at thoracolumbar region (Table 5).

Ninety-eight percent of these patients were transported for medical aid in vehicles without proper positioning or special consideration for SCI. One thousand four hundred ninety-five patients (55\%) were initially admitted to primary health centers, where specialized services were unavailable, resulting in delay of initial medical aid. In our series,

Table 1 Distribution as per AIS (ASIA Impairment Scale) grade $(n(\%))$ in patients with spinal cord injury

\begin{tabular}{lccc}
\hline Als grade & $\begin{array}{c}\text { Cervical, } \mathrm{n}=1400 \\
(\%)\end{array}$ & $\begin{array}{c}\text { Thoracolumbar, } \mathrm{n}=1316 \\
(\%)\end{array}$ & $\begin{array}{c}\text { Total, } \mathrm{n}=2716 \\
(\%)\end{array}$ \\
\hline A & 20.5 & 23.4 & 43.9 \\
B & 3.6 & 2.8 & 6.4 \\
C & 5.3 & 2.7 & 8.0 \\
D & 10.7 & 5.7 & 16.4 \\
E & 6.4 & 6.6 & 13.0 \\
Not Tested & 5 & 7.3 & 12.3 \\
\hline
\end{tabular}

Abbreviations: ASIA, American Spinal Injury Association; $n$, number of patients. Grade E: According to initial examination and history had some deficit which recovered when admitted and examined in rehabilitation unit.

Table 2 Age and gender distribution in rural and urban population in patients with spinal cord injury as compared with percentage distribution in the general population (\%)

\begin{tabular}{|c|c|c|c|c|c|c|}
\hline \multirow{3}{*}{$\begin{array}{l}\text { Age } \\
\text { group } \\
\text { (years) }\end{array}$} & \multirow{3}{*}{$\begin{array}{c}\text { Age } \\
\text { distribution } \\
\text { in the } \\
\text { general } \\
\text { population } \\
\text { (\%) }\end{array}$} & \multirow{3}{*}{$\begin{array}{c}\text { Distribution } \\
\text { among } \\
\text { patients } \\
\text { with spinal } \\
\text { cord } \\
\text { injuries (\%) }\end{array}$} & \multicolumn{4}{|c|}{ Gender } \\
\hline & & & \multicolumn{2}{|c|}{ Male } & \multicolumn{2}{|c|}{ Female } \\
\hline & & & $\begin{array}{c}\text { Rural } \\
\text { (\%) }\end{array}$ & $\begin{array}{c}\text { Urban } \\
\text { (\%) }\end{array}$ & $\begin{array}{c}\text { Rural } \\
\text { (\%) }\end{array}$ & $\begin{array}{c}\text { Urban } \\
\text { (\%) }\end{array}$ \\
\hline$<19$ & 50.8 & 12.6 & 55.1 & 14.1 & 18.8 & 12.0 \\
\hline 20-49 & 37.2 & 71.1 & 66.7 & 16.4 & 13.1 & 3.8 \\
\hline 50-69 & 9.5 & 14.4 & 66.0 & 14.6 & 12.2 & 7.2 \\
\hline$\geqslant-70$ & 2.5 & 1.9 & 63.0 & 11.1 & 22.2 & 3.7 \\
\hline
\end{tabular}

an average delay of $11 \mathrm{~h}$ and 5 days was noted for bladder and bowel management, respectively.

\section{DISCUSSION}

The knowledge of the epidemiology of SCI in a country is important for planning and developing resources to provide adequate treatment and rehabilitation, as it has significant personal, bio-psychological impact and socio-economic consequences. ${ }^{16}$

Data in most of the earlier studies were noted retrospectively except in the study by Chen et al. ${ }^{7}$ Ours was a prospective collection of data of patients with SCI.

The male to female ratio varied from $1.6: 1$ to $13.5: 1$ in different studies. ${ }^{1-3,5-14,16-18}$ We found that males were four times (4.2:1) more prone for SCI when compared with females. This could be due to the fact that in most families, males are primary earning member of the family and hence get exposed to greater risk. Seventy-one percent were in the age range of 20-49 years which is in accordance with previous studies. $^{1-5,8-11,14,16,17,19}$ This is an alarming condition where the most active human resource is becoming severely disabled resulting in loss of family earning in nuclear families (51.1\%). This affects their day-today life, including medical treatment due to financial constraints and non-availability of care taker. Joint families overcome this problem $(30.6 \%)$ to some extent where other members of the family are likely to support the patient and his family.

One thousand twenty-eight patients $(37.8 \%)$ were uneducated and had to work as manual labor in farming and other risky jobs, hence were more prone for SCI. In rural settings, falls ${ }^{17,19}$ (especially from tree $)^{17}$ were common resulting in more thoracolumbar injuries. ${ }^{1}$ RTA was major cause of SCI in western countries and urban population ${ }^{1,17}$ resulting in more cervical injuries. ${ }^{1}$ There are certain uncommon causes of SCI such as fall with heavy object overhead. ${ }^{16}$ SCI following fall from height ranges from 9.4 to $48.7 \% .^{6,9,13,16,17,19}$ In our study, 2145 cases $(79.0 \%)$ of SCI patients were from rural area and 1145 cases $(42.0 \%)$ sustained injuries following fall from height. We observed that in rural area the parapets on the roof of houses and side wall of stairs are either of low height or completely lacking making them a source of fall. Fall from tree is a major cause of injury in rural settings ${ }^{14,17}$ as 143 patients (5.3\%) sustained injury following fall from tree. Most of the children in rural area climb trees for playing

Table 3 Relation between rural/urban population in patients with spinal cord injury and gender distribution with different types of job (\%)

\begin{tabular}{|c|c|c|c|c|c|}
\hline \multirow[t]{2}{*}{ Job } & \multirow{2}{*}{$\begin{array}{c}\text { Total no. } \\
\text { (2716) (\%) }\end{array}$} & \multicolumn{2}{|c|}{ Rural } & \multicolumn{2}{|c|}{ Urban } \\
\hline & & Male (\%) & Female (\%) & Male (\%) & Female (\%) \\
\hline Farmer & 23.2 & 86.1 & 8.1 & 5.5 & 0.3 \\
\hline Laborer & 22.9 & 79.1 & 2.9 & 17.0 & 1.0 \\
\hline House wife & 12.8 & - & 73.2 & - & 26.8 \\
\hline Business & 8.3 & 63.6 & 1.3 & 35.1 & - \\
\hline Student & 9.0 & 60.8 & 11.8 & 16.3 & 11.1 \\
\hline Clerical job & 5.5 & 68.0 & 1.3 & 30.0 & 0.7 \\
\hline Driver & 4.6 & 80.0 & - & 20.0 & - \\
\hline Mechanic & 2.4 & 75.0 & - & 25.0 & - \\
\hline Private job & 4.1 & 60.0 & 0.9 & 38.2 & 0.9 \\
\hline Teacher & 1.7 & 73.3 & 4.4 & 18.2 & 4.4 \\
\hline Electrician & 0.7 & 85.0 & - & 15.0 & - \\
\hline Not working & 3.0 & 56.6 & 14.5 & 19.3 & 9.6 \\
\hline Miscellaneous & 1.8 & 56.2 & 10.4 & 27.1 & 6.3 \\
\hline
\end{tabular}


and sustain injury during jumps or accidental fall. Adults sustained injuries when they climb trees for cutting dry wood (commonly used as fuel for cooking) or for harvesting green leaves for cattle feed.

In rural areas of the state of Rajasthan, major source of drinking water are wells. Due to lack of rains, these wells require regular digging and repair of equipments. During these activities, accidental fall in well or fall of heavy object or mud over head or back results in SCI. At the same time, some of these unserviceable wells are dry and are not maintained properly or closed. In 291 patients (10.7\%), the cause of spinal trauma was fall of heavy weight over their heads or back while working in well or fall of grain bags while stocking or taking out these bags from storing places. Hoque et al. ${ }^{16}$ have reported $20 \%$ of their patient sustained SCI following fall while carrying objects of heavy weight on head which is much less in our study as only 84 patients (3.0\%) sustained trauma to spine following loss of balance and fall while carrying heavy load on the head. This is a common practice of transporting weight in developing countries, ${ }^{16}$ which acts as the compressive force resulting in injuries.

RTA is another common cause of SCI in developed countries ranging from 35.0 to $77.4 \%$ of total injuries. ${ }^{1-5,7,8,10-12,14,18,20}$ In our study, $762(26.9 \%)$ cases sustained injury following RTA. This low incidence rate could be due to low average driving speed in India as compared with western countries.

An unusual cause of SCI noted in our series was fall following electric shock. To date, no other study has reported this mode of injury. There were 110 cases $(4.0 \%)$ in our study who sustained SCI along with associated electrical burn wounds over 64 different sites, which required special care from plastic surgeons.

The incidence of cervical (51.5\%) and thoracic (48.5\%) injuries was found in our study which was comparable to the incidence as reported by Martin et al. ${ }^{18}$ in the ratio of 51.2:48.8. The incidence of complete tetraplegia and paraplegia (AIS A) in different studies varies from 4.8 to $50.6 \%$ and 16.0 to $85.1 \%$, respectively. ${ }^{1,3-5,7,9-14,16,19}$ We found 557 cases $(20.5 \%)$ of cervical and 633 cases $(23.3 \%)$ of thoracolumbar belonging to AIS A. In all, 136 cases (5.0\%) in cervical and 199 (7.3\%) in thoracolumbar cases were in the 'not tested group' due to associated injuries (Table 1). The incidence of associated injuries in other studies varies from 21.4 to $52.0 \% .^{7,9,10,18}$ We found 699 cases $(25.7 \%)$ who sustained different types of associated trauma which is comparable. However, the rate is low in our study which could be attributed to lower RTA in our series when compared with previous studies. ${ }^{7,10,18}$ Such injuries were managed by orthopedic surgeons. During early management, such patients are immobilized with splint or skeletal traction, thus making patients more prone to develop pressures sores. Head injuries were the next common associated injury. The delay in recovery from head injuries usually results in chest complications and pressure sore development. Chest injuries may require inter-costal drainage and cause difficulty in chest therapy. This again increases the risk of pressure sores and chest infection. The deep electric burns in upper extremities involving tendons, nerves and vessels are complicated and managed with difficulty in the rehabilitation unit. Hence, these patients not only require active early surgical intervention for prevention of complications but also require active multidisciplinary approach.

Placement of urinary catheter and daily evacuation of bowel is essential in management of SCI patients. In our series, a total of $55 \%$ patients were initially attended by centers where specialized services and trained medical staff were not available resulting in average delay of $11 \mathrm{~h}$ and 5 days in bladder and bowel management, respectively. This indicates lack of training of medical professionals at the primary health centers with respect to SCI. 
Table 5 Various associated injuries with spinal cord injury (\%)

\begin{tabular}{|c|c|c|c|}
\hline Associated injuries & Cervical, $\mathrm{n}=334$ (\%) & Thoracolumbar, $\mathrm{n}=365(\%)$ & Total, $\mathrm{n}=699(\%)$ \\
\hline Head injury & 33.5 & 22.7 & 27.8 \\
\hline Single fracture-Extremity & 27.2 & 28.2 & 27.7 \\
\hline Multiple fractures-Extremities & 6.2 & 20.0 & 13.4 \\
\hline Multiple rib fractures & 1.5 & 12.6 & 7.3 \\
\hline Abdominal injury & 0.1 & 2.2 & 1.3 \\
\hline Other injuries along with abdominal injury (chest, head) & Nil & 0.1 & 0.4 \\
\hline Peripheral nerve injuries & 0.2 & 0.1 & 0.5 \\
\hline Multiple injuries (foot, wrist, eye, nose, back) & 2.9 & 3.2 & 3.1 \\
\hline Amputation (fingers, upper limb, pinna) & 1.5 & 1.4 & 1.4 \\
\hline Miscellaneous & 26.9 & 9.5 & 17.1 \\
\hline
\end{tabular}

The limitation of this prospective study is that only data from our spinal unit were analyzed. Rajasthan has got five more medical colleges who also cater to SCI patients. We also excluded those patients who were treated at district hospital. Though our spinal unit is the largest referral unit in Rajasthan but still this could have resulted in a low incidence of SCI.

To summarize, epidemiological and demographic data of SCI in Indian scenario are different from western countries with major cause being fall and not RTA. Measures such as increasing the height of parapets on the top roof, side walls of stairs and closing down of dry well in rural area may reduce the incidence of SCI. Similarly educating the children and preventing them from climbing tree may further reduce the incidence. The low socio-economic status and the younger age group of the patients have a major economic, social and psychological impact. Various government agencies should work in liaison in imparting education, increasing awareness about prevention of SCI along with taking remedial measures to correct the factors causing SCI. Primary health-care providers should be given training regarding the primary management of SCI. The patients of SCI and their families should be given the necessary psycho-social rehabilitation so that they can lead a respectable life.

\section{DATA ARCHIVING}

There were no data to deposit.

\section{CONFLICT OF INTEREST}

The authors declare no conflict of interest.

\section{ACKNOWLEDGEMENTS}

We thank all the staff of Department of Physical Medicine and Rehabilitation, SMS Medical College, Jaipur, Dr Sushma Mathur, Dr Mrinal Joshi, Dr Sunil Goenka, Dr Rajeshwari Jindal and Dr Sonu Singh.

1 Biering-Sørensen F, Pedersen V, Clausen S. Epidemiology of spinal cord lesions in Denmark. Paraplegia 1990; 28: 115-118.

2 Parsons KC, Lammertse DP. Rehabilitation in spinal cord disorders. Epidemiology, prevention, and system of care of spinal cord disorders. Arch Phys Med Rehabil 1991; 72: S293-S294.

3 Lan C, Lai JS, Chang KH, Jean YC, Lien IN. Traumatic spinal cord injuries in the rural region of Taiwan: an epidemiological study in Hualien county, 1986-1990. Paraplegia 1993; 31: 398-403.
4 Price C, Makintubee S, Herndon W, Istre GR. Epidemiology of traumatic spinal cord injury and acute hospitalization and rehabilitation charges for spinal cord injuries in Oklahoma, 1988-1990. Am J Epidemiol 1994; 139: 37-47.

5 Shingu H, Ikata T, Katoh S, Akatsu T. Spinal cord injuries in Japan: a nationwide epidemiological survey in 1990. Paraplegia 1994; 32: 3-8.

6 Karamehmetoğlu ŞS, Ünal Ş, Karacan I, Yílmaz H, Togay HŞ, Ertekin M et al. Traumatic spinal cord injuries in Istanbul, Turkey. An epidemiological study. Paraplegia 1995; 33: 469-471.

7 Chen HY, Chiu WT, Chen SS, Lee LS, Hung Cl, Hung CL et al. A nationwide epidemiological study of spinal cord injuries in Taiwan from July 1992 to June 1996. Neurol Res 1997; 19: 617-622.

8 Otom AS, Doughan AM, Kawar JS, Hattar EZ. Traumatic spinal cord injuries in Jordan. An epidemiological study. Spinal Cord 1997; 35: 253-255.

9 Karamehmetoğlu SS, Nas K, Karacan İ, Sarac AJ, Koyuncu H, Ataoğlu S et al. Traumatic spinal cord injuries in Southeast Turkey: An epidemiological study. Spinal Cord 1997; 35: 531-533.

10 Karacan I, Koyuncu H, Pekel Ö, Sümbüloğlu G, Kırnap M, Dursun H et al. Traumatic spinal cord injuries in Turkey: A nation-wide epidemiological study. Spinal Cord 2000; 38: 697-701.

11 O'Connor P. Incidence and patterns of spinal cord injury in Australia. Accid Anal Prev 2002; 34: 405-415.

12 Pickett GE, Campos-Benitez M, Keller JL, Duggal N. Epidemiology of traumatic spinal cord injury in Canada. Spine 2006; 31: 799-805.

13 Van Asbeck FWA, Post MWM, Pangalila RF. An epidemiological description of spinal cord injuries in The Netherlands in 1994. Spinal Cord 2000; 38: 420-424.

14 Dincer F, Oflazer A, Beyazova M, Çeliker R, Basgöze O, Altioklar K. Traumatic spinal cord injuries in Turkey. Paraplegia 1992; 30: 641-646.

15 Kirshblum SC, Burns SP, Biering-Sorensen F, Donovan W, Graves DE, Jha A et al. International standards for neurological classification of spinal cord injury (revised 2011). J Spinal Cord Med 2011; 34: 535-546.

16 Hoque MF, Grangeon C, Reed K. Spinal cord lesions in Bangladesh: an epidemiological study 1994-1995. Spinal Cord 1999; 37: 858-861.

17 Chacko V, Joseph B, Mohanty SP, Jacob T. Management of spinal cord injury in a General Hospital in Rural India. Paraplegia 1986; 24: 330-335.

18 Martins F, Freitas F, Martins L, Dartigues JF, Barat M. Spinal cord injuries: Epidemiology in Portugal's central region. Spinal Cord 1998; 36: 574-578.

19 Kiwerski E. The causes, sequelae and attempts at prevention of cervical spine injuries in Poland. Paraplegia 1993; 31: 527-533.

20 DeVivo MJ. Causes and costs of spinal cord in the United States. Spinal Cord 1997; 35 : 809-813.

\section{APPENDIX}

1. Urban Area: All statutory places with a municipality, corporation, cantonment board or notified town area committee.

2. Rural area: All other areas not coming under urban area.

3. Nuclear family: Family with patient, wife and children.

4. Joint family: Extended nuclear family with families of sibling of patient. 